\title{
Inhibition of breast cancer cell survival by Xanthohumol via modulation of the Notch signaling pathway in vivo and in vitro
}

\author{
ZHIHONG SUN $^{1 *}$, CHENG ZHOU $^{1 *}$, FENG LIU $^{1}$, WENCHAO ZHANG ${ }^{1}$, JING CHEN $^{1}$, \\ YANLONG PAN $^{1}$, LIANQING MA ${ }^{2}$, QIMIN LIU ${ }^{2}$, YUPING DU ${ }^{1}$, JINBO YANG $^{1}$ and QIN WANG ${ }^{1}$ \\ ${ }^{1}$ School of Life Sciences, Lanzhou University, Lanzhou; ${ }^{2}$ Yumen Tuopu Science Development and Technology Co., Ltd., \\ Yumen, Gansu 730000, P.R. China
}

Received November 18, 2015; Accepted January 13, 2017

DOI: $10.3892 / \mathrm{ol} .2017 .7434$

\begin{abstract}
Natural compounds derived from plants have been an important source of numerous clinically useful anticancer agents. Nevertheless, limited studies indicate that xanthohumol (XN), a major prenylated flavonoid in hop plants (Humulus lupulus), may possess anticarcinogenic properties. The purpose of the present study was to clarify the antitumorigenic effects and the underlying mechanism of $\mathrm{XN}$ on breast cancer in vivo and in vitro. A $4 \mathrm{~T} 1$ breast tumor mouse model was used in the present study to investigate XN suppression of tumor growth as detected by tumorigenicity assays in vivo. In addition, in vitro studies revealed that $\mathrm{XN}$ significantly decreased cell viability, induced $\mathrm{G}_{0} / \mathrm{G}_{1}$ cell cycle arrest and apoptosis in MCF-7 and MDA-MB-231 cells, as confirmed by an MTT assay, flow cytometry and western blot analysis, indicating anticarcinogenic activity of XN against breast cancer. Furthermore, immunohistochemistry was performed to confirm the inactivation of the Notch signaling pathway, Notch 1 and Ki-67, in vivo; consistently, XN caused decreased activation of the Notch signaling pathway and apoptotic regulators B-cell lymphoma-2 (Bcl-2), Bcl-extra large and caspase 3, as determined by western blot analysis in vitro. This study suggests that XN may potentially be useful as a chemopreventive agent during breast hyperplasia and carcinogenesis, acting via the regulation of Notch associated apoptotic regulators in vivo and in vitro.
\end{abstract}

\section{Introduction}

Breast cancer is the most common type of cancer in females and one of the most devastating cancers worldwide $(1,2)$. Although the underlying mechanism that causes breast cancer

Correspondence to: Professor Qin Wang, School of Life Sciences, Lanzhou University, 222 Tianshui Road, Lanzhou, Gansu 730000, P.R. China

E-mail: qwang@lzu.edu.cn

*Contributed equally

Key words: xanthohumol, Notch signaling pathway, apoptosis, cell cycle, migration, breast cancer remains uncertain, substantial evidence suggests that the Notch signaling pathway may serve an important role in breast cancer pathogenesis and, thus, may be a novel therapeutic target $(3,4)$.

The Notch pathway serves an important role in normal breast cell development, cell fate determination and stem cell self-renewal (3). It is also implicated in breast cancer development and progression as the aberrant activation of this pathway is associated with breast cancer (3-5). Inhibition of Notch signaling by gamma secretase inhibitors, anti-Notch1 or anti-delta-like 4 (DLL4) monoclonal antibodies have been revealed to result in antitumor activity in a variety of tumors, including T-cell acute lymphoblastic leukemia (T-ALL) and solid tumors, through multiple mechanisms inclusive of the induction of cell cycle arrest or apoptosis, and also the disruption of angiogenesis (4-10). Notch signaling serves important roles in various physiological and pathological processes including cell differentiation, proliferation, invasion, angiogenesis, tumor metastasis and apoptosis, which contribute to the development of various types of human cancer $(5,11)$. Furthermore, an activated Notch signaling pathway and its target genes are commonly observed in breast cancer, and the upregulation of Notchl expression has been revealed to protect breast cancer cells from apoptosis (12). Currently known gene targets for Notch signaling include the hairy enhancer of split (Hes) genes, p21, cyclinD1, $c-M y c$, nuclear factor $\kappa \mathrm{B}$, B-cell lymphoma-2 (Bcl-2) and Bcl-extra large (Bcl- $x l)(13-18)$.

Previous studies suggest that xanthohumol (XN), a prenylated chalcone derived from hops (Humulus lupulus), may inhibit cell growth and induce apoptosis in numerous types of human cancer, including breast, prostate, leukemia and colon cancer cells (19-23); however, the underlying mechanism of this inhibition remains unknown. In the present study, the therapeutic potential of $\mathrm{XN}$ in breast cancer cell lines was investigated, focusing on its ability to inhibit breast cancer cell proliferation, cell cycle arrest, apoptosis induction in vitro and slowing tumor growth in vivo. Additionally, possible $\mathrm{XN}$-mediated inhibition in human breast cancer growth via the regulation of the Notchl signaling pathway was investigated. To the best of our knowledge, the present study was the first to observe that XN suppressed breast carcinoma growth by inhibiting the Notch signaling pathway in vitro and in vivo. Therefore, blocking of the Notch signaling pathway may be a 
novel therapeutic approach for the treatment of breast cancer by inhibiting tumor development, progression and metastasis.

\section{Materials and methods}

Cell lines and cell culture. Human MCF-7, MDA-MB-231 and HEK-293T cells, h-TERT-BJ, MCF-10A and murine 4T1 cells were obtained from the American Type Culture Collection (Manassas, VA, USA). They were cultured in Dulbecco's modified Eagle's medium (DMEM; Gibco; Thermo Fisher Scientific, Inc., Waltham, MA, USA) supplemented with $10 \%$ fetal bovine serum (FBS; Thermo Fisher Scientific, Inc.) and maintained at $37^{\circ} \mathrm{C}$ in a humidified atmosphere of $5 \% \mathrm{CO}_{2}$ in air.

Animals. All studies evaluating in vivo toxicity and therapeutic effectiveness were performed using 26 female BALB/c mice (17-18 g; 8 weeks of age) and obtained from Lanzhou Veterinary Research Institute, Chinese Academic of Agricultural Sciences (Lanzhou, China). The Institutional Animal Care and Use Committee of Lanzhou University approved use of BALB/c mice for the present study, and procedures involving animals and their care complied with the Guide for the Care and Use of Laboratory Animals. Mice were maintained in a temperature-controlled $\left(23 \pm 4^{\circ} \mathrm{C}\right)$ environment with a strict $12 \mathrm{~h}$ light/dark cycle. Food was purchased from Wanqianjiaxing Biotech Corp (Wuhan, China) and water was autoclaved. Food and water were freely available to the mice.

Reagents and antibodies. XN (purity 98.6\%) was provided by Yumen Tuopu Science Development and Technology Co., Ltd. (Yumen, China). Duration of Dual Antiplatelet Therapy (DAPT) was purchased from Sigma-Aldrich (Merck Millipore, Darmstadt, Germany). Primary antibodies against Notch 1 (120 kDa; cat. no., 3268; dilution, 1:1,000), p21 (cat. no., 2947; dilution, 1:1,000), cyclin-dependent kinase 4 (CDK4) (cat. no., 12790; dilution, 1:1,000), c-Myc (cat. no., 5605; dilution, 1:1,000), survivin (cat. no., 2808; dilution, 1:1,000), Bcl-2 (cat. no., 15071; dilution, 1:500), Bcl-xL (cat. no., 2764; dilution, 1:1,000), cyclin D1 (cat. no., 2978; dilution, 1:1,000), caspase-3 (cat. no., 9665; dilution, 1:1,000) and poly (ADP-ribose) polymerase (PARP; cat. no., 9532; dilution, 1:1,000) were purchased from Cell Signaling Technology, Inc. (Danvers, MA, USA). Hes1 (cat. no., ABIN2779597; dilution, 1:1,000) was acquired from Abnova Biotechnology (Taipei, Taiwan ROC). GAPDH (cat. no., sc-47724; dilution, 1:5,000) was supplied by Santa Cruz Biotechnology, Inc. (Dallas, TX, USA). The secondary antibodies, peroxidase-conjugated AffiniPure goat anti-rabbit (cat. no., ZB-2301; dilution, 1:500) and anti-mouse (cat. no., ZB-2305; dilution, 1:500) IgG (H+L), were purchased from ZSGB-Bio (Beijing, China).

MTT assay. The h-TERT-BJ, MCF-10A, MCF-7 and MDA-MB-231 cells $\left(5 \times 10^{3}\right)$ were seeded in a 96-well culture plate; following a 24-h incubation the cells were treated with 5, 10,15 and $25 \mu \mathrm{mol} / 1 \mathrm{XN}$ for 24 and $48 \mathrm{~h}$ in incubator. Control cells were treated with $0.1 \%$ dimethyl sulfoxide (DMSO) in culture medium. Following treatment, the cells were incubated with MTT reagent $(0.5 \mathrm{mg} / \mathrm{ml})$ at $37^{\circ} \mathrm{C}$ for $4 \mathrm{~h}$. The resulting formazan crystals were solubilized by the addition of $200 \mu \mathrm{l}$
DMSO to each well. The absorbance was read at $490 \mathrm{~nm}$ in a Vector3 Multilevel Plate Counter (PerkinElmer, Inc., Waltham, MA, USA) and all MTT experiments were performed in triplicate and repeated $\geq 3$ times.

Transient transfection and luciferase reporter assay. Transient transfections were performed with Lipofectamine ${ }^{\circledR}$ (Invitrogen; Thermo Fisher, Inc.), according to the manufacturer's protocol. Briefly, HEK-293T cells were plated in 24 -well plates at a density of $1 \times 10^{5}$ cells/well. Following a 24-h incubation at $37^{\circ} \mathrm{C}$, cells were transfected with plasmids of $0.8 \mu \mathrm{g}$ promoter-linked luciferase vector $(23 \mathrm{~A}, 4 \mathrm{xCBF} 1$ binding element plasmid) and $0.2 \mu \mathrm{g}$ pGL4.20 vector for $4 \mathrm{~h}$ in DMEM (Sigma-Aldrich; Merck Millipore). Following DLL-4 (100 ng/ml) stimulation, cells were treated with XN for $12 \mathrm{~h}$ at $37^{\circ} \mathrm{C}$. The cell lysates were evaluated in a luciferase assay using a dual luciferase reporter assay kit (E1910; Promega, Madison, WI, USA), and the emitted light was determined with a luminometer (Wallac 1420 VICTOR, Inc., Waltham, MA, USA) as previously described (24). Luciferase activity was normalized to $\beta$-galactosidase and plotted as relative light units.

Flow cytometry analysis of cell cycle. The cell cycle was analyzed by flow cytometry. The MCF-7 and MDA-MB-231 cells $\left(1 \times 10^{6}\right)$ were collected and washed in PBS, prior to being fixed in $75 \%$ alcohol at $20^{\circ} \mathrm{C}$ overnight. Following washing in cold PBS three times, cells were resuspended in $1 \mathrm{ml}$ PBS solution with $50 \mu \mathrm{g}$ propidium iodide (PI; Sigma-Aldrich; Merck Millipore) and $100 \mu \mathrm{g}$ RNase A (Sigma-Aldrich; Merck Millipore), for $30 \mathrm{~min}$ at $37^{\circ} \mathrm{C}$. Samples were then analyzed for their DNA content by fluorescence-activated cell sorting (FACS; BD Biosciences, San Jose, CA, USA). Each experiment was repeated $\geq 3$ times.

Flow cytometric analysis of apoptosis. Cell apoptosis was assessed by flow cytometry using an Annexin-V-fluorescein isothiocyanate/PI apoptosis detection kit (BD Biosciences, San Jose, CA, USA), according to the manufacturer's instructions. The pretreated MCF-7 and MDA-MB-231 cells were harvested and washed twice with $\mathrm{PBS}\left(4^{\circ} \mathrm{C}\right)$. Following this, they were resuspended in $1 \mathrm{X}$ binding buffer at a concentration of $1 \times 10^{6}$ cells $/ \mathrm{ml}$, stained with Annexin V/PI and kept on ice for $30 \mathrm{~min}$ in the dark. The cells were then analyzed on a FACSCalibur ${ }^{\mathrm{TM}}$ flow cytometer (BD Biosciences). Assays were performed three times in triplicate.

Semi-quantitative reverse transcription polymerase chain reaction ( $R T-P C R)$. Total RNA was isolated from cell lines using an RNeasy kit as described by the manufacturer (Qiagen Inc., Valencia, CA, USA). The reverse transcription reaction was performed using the SuperScript ${ }^{\circledR}$ First-Strand Synthesis System (Invitrogen; Thermo Fisher Scientific, Inc.) in a final volume of $20 \mu \mathrm{l}$, containing $5 \mu \mathrm{g}$ total RNA, $200 \mathrm{ng}$ random hexamers, $1 \mathrm{X}$ reverse transcription buffer, $2.5 \mathrm{mM} \mathrm{MgCl}$, $1 \mathrm{mM}$ deoxynucleotide triphosphate mixture, $10 \mathrm{mM}$ DTT, RNaseOUT recombinant ribonuclease inhibitor (Invitrogen; Thermo Fisher Scientific, Inc.), 50 U superscript reverse transcriptase and diethylpyrocarbonate-treated water. Following incubation at $42^{\circ} \mathrm{C}$ for $50 \mathrm{~min}$, the reverse transcription 
reaction was terminated by heating to $85^{\circ} \mathrm{C}$ for $5 \mathrm{~min}$. The newly synthesized cDNA was amplified by PCR. The reaction mixture contained $2 \mu \mathrm{l}$ cDNA template, $1.5 \mathrm{mM} \mathrm{MgCl}_{2}, 2.5 \mathrm{U}$ Taq polymerase and $0.5 \mu \mathrm{M}$ primers (primers are presented in Table I). The reactions were performed under the following conditions: $5 \mathrm{~min}$ at $94^{\circ} \mathrm{C}, 30 \mathrm{sec}$ at $94^{\circ} \mathrm{C}, 30 \mathrm{sec}$ at $55^{\circ} \mathrm{C}$, $30 \mathrm{sec}$ at $72^{\circ} \mathrm{C}, 25$ cycles of $30 \mathrm{sec}$ at $94^{\circ} \mathrm{C}, 5 \mathrm{~min}$ at $72^{\circ} \mathrm{C}$ and $30 \mathrm{~min}$ at $4^{\circ} \mathrm{C}$. The mRNA levels of Hesl and Hes related family BHLH transcription factor with YRPW motif 1 (Heyl) were normalized to GAPDH.

Boyden chamber assay. For Boyden chamber assays, 1x10 MDA-MB-231 cells were seeded per well in a Boyden chamber with a pore size of $8 \mu \mathrm{M}$ (Corning Incorporated, Corning, NY, USA), without fetal bovine serum. For the control and treated samples (following XN and DAPT treatment), the lower compartment was filled with medium containing $10 \%$ FBS. Following 6 or 12 h, cells were fixed with $4 \%$ paraformaldehyde solution and stained with crystal violet (Beyotime Institute of Biotechnology, Haimen, China; C0121). Cells on top of the filter were removed with a cotton bud and the bottom sides were photographed using a bright field light microscope (4x objective). For quantification, the membranes sectioned, and $0.1 \mathrm{ml} \mathrm{33 \%}$ acetic acid elution was used to dissolve the cells, then $40 \mu \mathrm{l}$ was added into 96 plates and the values were determined at $570 \mathrm{~nm}$.

Western blot analysis. Western blotting was performed as described in a previous study (24). Briefly, total proteins from the two human breast cancer cell lines were lysed in lysis buffer (cat. no., P00138; Beyotime Institute of Biotechnology) and incubated for $15 \mathrm{~min}$ at $4^{\circ} \mathrm{C}$. The concentrations of total proteins were determined using a bicinchoninic acid assay protein assay kit (Thermo Fisher Scientific, Inc.). Total proteins were fractionated using 10\% SDS-PAGE and the gels were then transferred onto a nitrocellulose membrane. The membranes were blocked with $5 \%$ non-fat milk in Tris-buffered saline containing $0.1 \%$ Tween-20 prior to incubation with the appropriate primary antibodies overnight at $4^{\circ} \mathrm{C}$. Horseradish peroxidase-conjugated anti-goat IgG was used as the secondary antibody, and the protein bands were detected using the electrochemiluminescence (ECL) method (cat. no., RPN2134; Western Blotting Detection Reagent, GE Healthcare Life Sciences, Chalfont, UK). Western blot analysis was quantified by laser densitometry, and the results are presented as the mean of three independent experiments with error bars representing the standard deviation.

In vivo tumorigenicity assays and immunohistochemistry. Firstly, 2x105 4T1 tumor cells from cultures, suspended in $0.2 \mathrm{ml}$ DMEM without FBS, were injected into the right flank of 8-week-old BALB/c mice. Tumor-bearing mice were randomly assigned in three groups $[n=10$ control mice; $n=16$ XN mice ( 8 received $100 \mathrm{mg} / \mathrm{kg} \mathrm{XN}$ and 8 received $200 \mathrm{mg} / \mathrm{kg}$ $\mathrm{XN})$ ]. Following 24-h, the mice were gavaged with $200 \mu \mathrm{l}$ vehicle or $200 \mu \mathrm{l} \mathrm{XN}$ at the appropriate concentrations (200 and $100 \mathrm{mg} / \mathrm{kg}$ ). Intragastric administration was performed once a day for two weeks and the mice were weighed daily. Following two weeks, all of the mice were sacrificed by breaking of the neck and the stripped subcutaneous sarcorna tumors were subsequently weighed to evaluated the antitumor effect. Tumors treated with $200 \mathrm{mg} / \mathrm{kg} \mathrm{XN}$ were stored in formaldehyde for immunohistochemistry as described in a previous study (25).

Statistical analysis. The statistical analysis was performed using SPSS, Inc., version 12.0 software (Chicago, IL, USA). All data were expressed as the mean \pm SD. Student's t-test was performed for comparisons between the two treatment groups. The three treatment groups were compared by one-way analysis of variance, followed by the significant difference method for multiple comparisons. $\mathrm{P}<0.05$ was considered to indicate a statistically significant difference and $\mathrm{P}<0.01$ was considered to indicate a highly statistically significant difference.

\section{Results}

$X N$ regulates Notchl signal pathway activity and downstream targets. In order to determine if the Notch pathway was targeted by XN, a Notchl functional assay and DAPT (gamma secretase inhibitor) was used as a positive control. Upon binding of Notchl to the CBF1 transgene, luciferase activity may be determined in the documented reporter assay. The aim of the present study was to determine if XN reduced the binding activity of Notchl to CBF1. The cells were stimulated with/without DLL-4 (100 ng/ml). The stimulated groups were treated with $\mathrm{XN}(5,10,20 \mu \mathrm{M})$ and DAPT (30 $\mu \mathrm{M})$. Relative to the control, a $62 \%$ and a $34 \%$ decrease in the luciferase signal were identified following treatment with $\mathrm{XN}(20 \mu \mathrm{M})$ and DAPT $(30 \mu \mathrm{M})$, respectively, for $24 \mathrm{~h}$ in $293 \mathrm{~T}$ cells (Fig. 1A). Subsequently, the level of XN, which was associated with a reduction in Notch 1 protein expression, was investigated. Cells were harvested following $24 \mathrm{~h}$ of treatment and analyzed by western blotting with antibodies specific for Notch 1 and Hes1 (Fig. 1B). Notch 1 and Hes1 expression levels decreased in a dose-dependent manner in both cell lines. This reduction in Notch 1 activity led to an evaluation into whether $\mathrm{XN}$ was functioning similar to a $\gamma$-secretase inhibitor, or if it is operating at the transcriptional level. RNA was isolated following one day of $\mathrm{XN}$ or DAPT treatment, and RT-PCR was performed. Lastly, the downstream target genes of Notch were investigated. It was revealed that treatment with $\mathrm{XN}$ resulted in decreased Hesl and Heyl transcription in MCF-7 and MDA-MB-231 cells. Concomitantly, a decrease in Hesl and Heyl transcription in MCF-7 and MDA-MB-231 cells was observed following treatment with DAPT (Fig. 1C).

$X N$ inhibits cell growth and migration in breast cancer cell lines. The treatment of MCF-7 and MDA-MB-231 breast cancer cells for 24-48 h with 5, 10, 15, 20 and $25 \mu \mathrm{M} \mathrm{XN}$ resulted in cell growth inhibition in a dose- and time-dependent manner, and the inhibition was revealed to be more pronounced with $25 \mu \mathrm{M}$ XN treatment by an MTT assay (Fig. 2A, left). Comparison of the effects on cell viability among MCF-7, MDA-MB-231, hTERT-BJ and MCF-10A cells following 24 and 48 h drug treatments (Fig. 2A, right), demonstrated that XN induced a higher level of apoptosis for DU145 and MDA-MB-231 cells compared with hTERT-BJ and MCF-10A cells, subsequent to treatment (Fig. 2A). The inhibition of cell 
Table I. Primer sequences for reverse transcription-polymerase chain reaction.

\begin{tabular}{lll}
\hline Gene & \multicolumn{1}{c}{ Upstream primer } & \multicolumn{1}{c}{ Downstream primer } \\
\hline Hesl & 5'-TTGGAGGCTTCCAGGTGGTA-3' & 5'-GGCCCCGTTGGGAATG-3' \\
Heyl & 5'-CGAGGTGGAGAAGGAGAGTG-3' & 5'-CTGGGTACCAGCCTTCTCAG-3' \\
GAPDH & 5'-TCTCATCACCATCTTCCA-3' & 5'-CATCACGCCACAGTTTCC-3'
\end{tabular}

Hes1, hairy enhancer of split 1; Hey1, Hes related family BHLH transcription factor with YRPW motif 1.

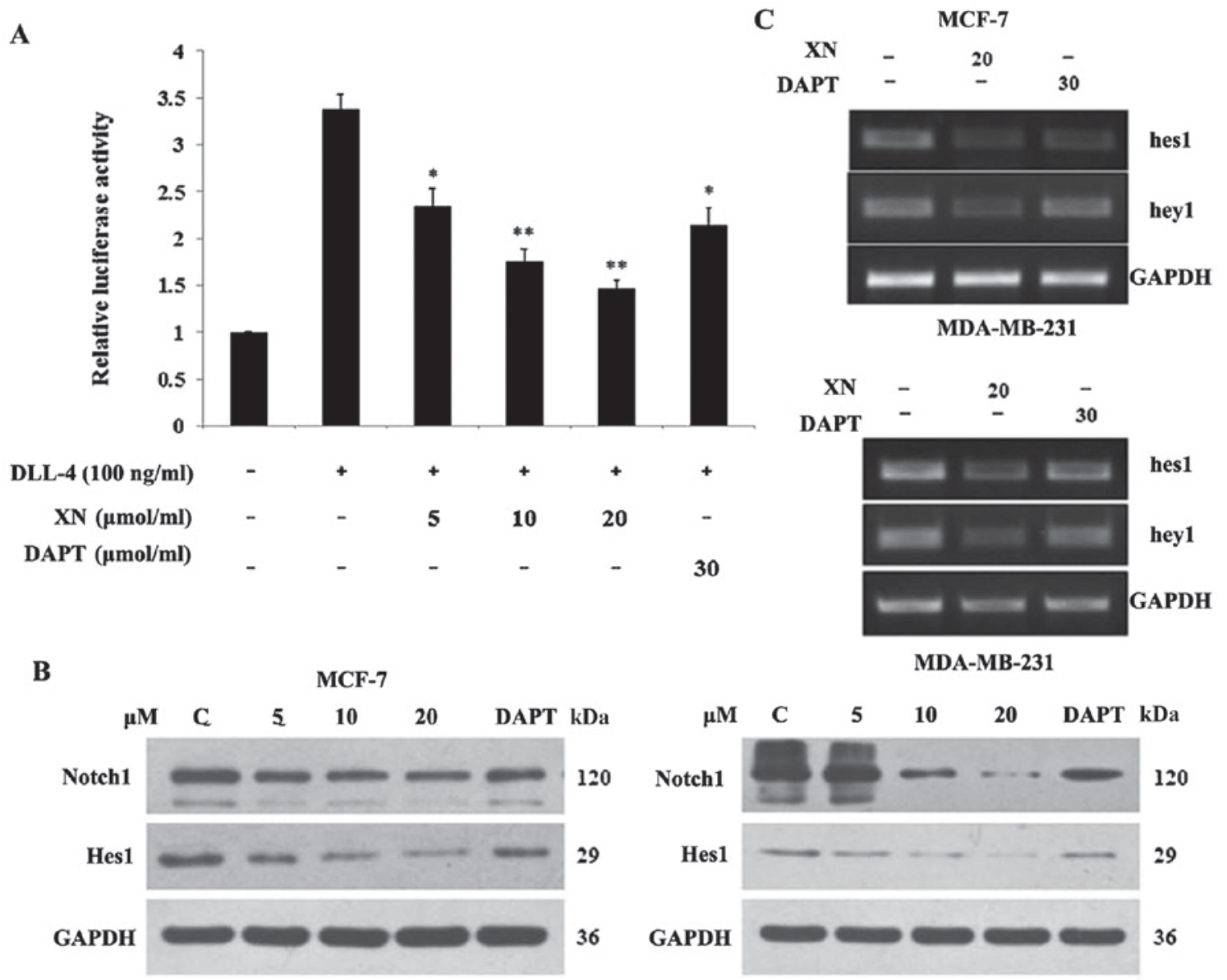

Figure 1. XN inhibited Notch1 activity. (A) XN inhibited Notchl-dependent luciferase activity. Luciferase data were normalized to $\beta$-galactosidase and are presented as the means $\pm \mathrm{SD} .{ }^{*} \mathrm{P}<0.05,{ }^{* *} \mathrm{P}<0.01$ vs. control. (B) Notch 1 and Hes1 protein expression levels were detected by western blotting. (C) XN inhibited Notch1-specific downstream gene Hesl and Heyl mRNA expression levels. DLL-4; anti-delta-like 4; DAPT, Duration of Dual Antiplatelet Therapy; Ctrl, control; XN, xanthohumol; Hesl, hairy enhancer of split 1; heyl, Hes related family BHLH transcription factor with YRPW motif 1.

growth was also identified by viewing with an inverted microscope (x10 magnification; Fig. 2B).

Western blot analysis of $\mathrm{c}-M y c$ and survivin was also performed. It has been observed that expression of $c-M y c$ and survivin were gradually decreasing compared with the control in both cell lines, following treatment with $\mathrm{XN}$ for $24 \mathrm{~h}$ (Fig. 2C). These results indicated that XN may inhibit breast cancer cell growth and migration by blocking the Notch 1 signaling pathway.

The effect of XN on the transmigration of MDA-MB-231 cells was determined with a Boyden chamber assay. Cell migration was inhibited significantly by XN treatment at 10 or $20 \mu \mathrm{M}$, down to 40 or $30 \%$, respectively. Similar effects $(83 \%)$ were observed with DAPT treatment, which was used as positive control (Fig. 2D and E). The effect of XN on epidermal growth factor receptor (EGFR) and tumor metastasis-associated protein (MIF) was determined by using a western blot assay. There was a notable decrease in EGFR expression levels and an increase in MIF expression levels, as the concentration of $\mathrm{XN}$ increased in the control and treatment groups in MDA-MB-231 cells (Fig. 2F).

$X N$ treatment is associated with cell cycle arrest and apoptosis. To determine whether cell cycle arrest was an underlying mechanism by which $\mathrm{XN}$ may be effecting reduced cell growth in breast cancer, the present study performed 
A

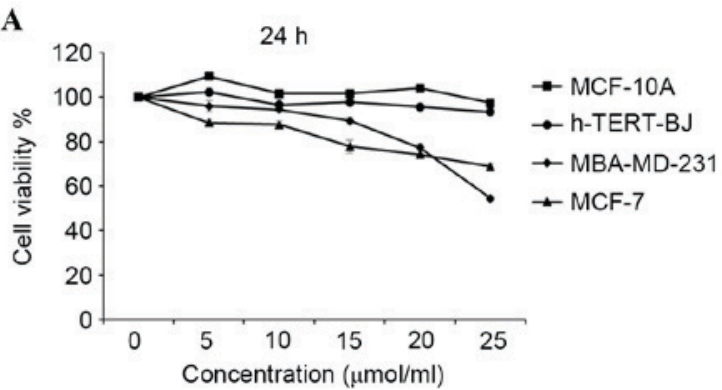

B
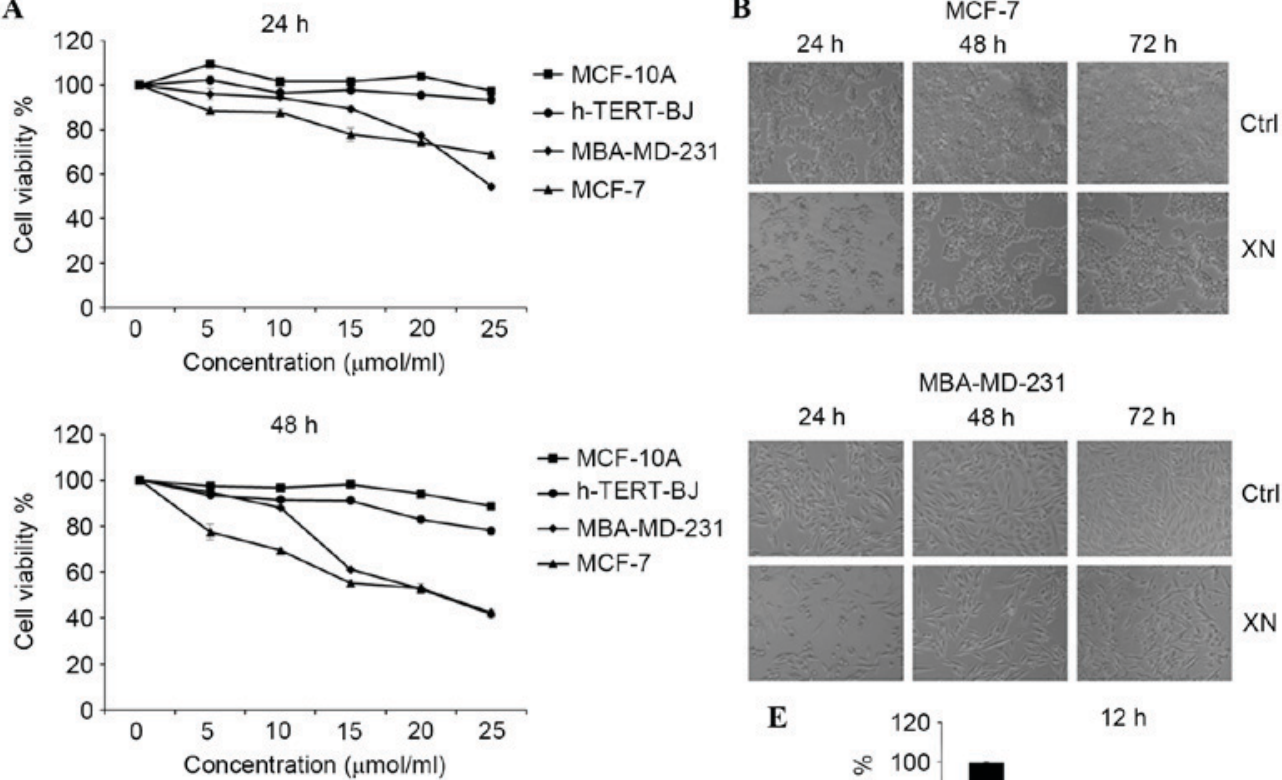

C

MCF-7

MDA-MB-231
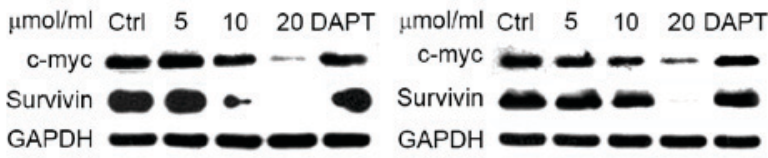

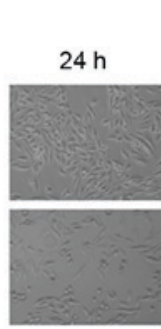

MBA-MD-231
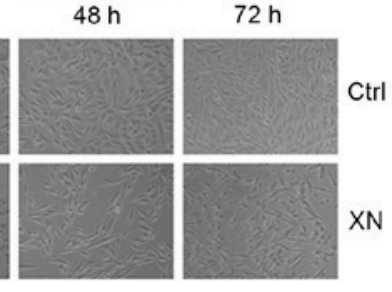

E

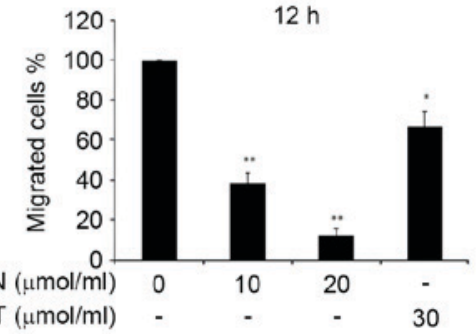

D
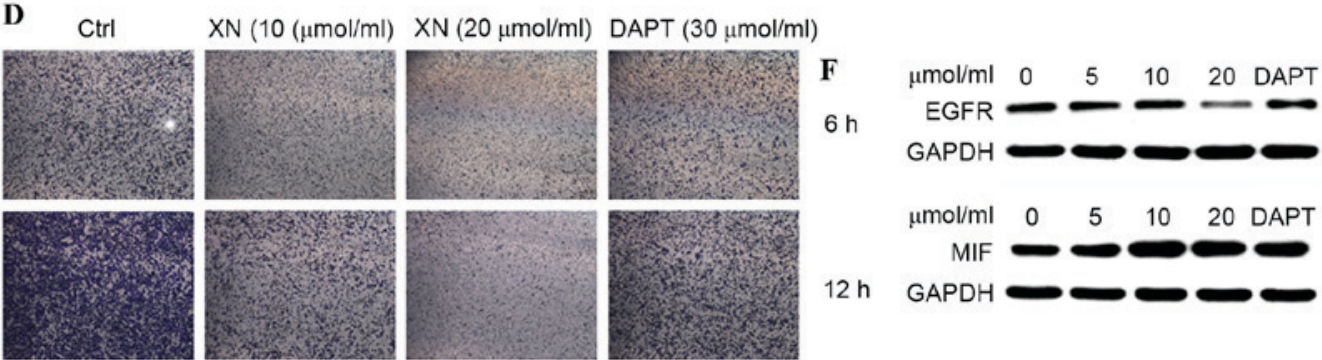

Figure 2. XN inhibited breast cancer cell proliferation in a dose- and time-dependent manner. (A) h-TERT-BJ, MCF-10A, MCF-7 and MDA-MB-231 were plated equally (six replicates) and treated with XN. MTT assays were performed daily for two days. DMSO was a vehicle control. (B) MDA-MB-231 and MCF-7 cells were treated with $20 \mu \mathrm{M} \mathrm{XN}$ for 24-72 $\mathrm{h}$ and visualized by light microscopy. (C) The c-Myc and survivin protein expression levels were detected by western blotting. (D) The Boyden chamber transwell assay demonstrated MDA-MB-231 cell migration. MCF-7 and MDA-MB-231 cells were treated with $\mathrm{XN}$ (data are presented as the mean \pm SEM of three independent experiments). (E) Quantification of migrated MDA-MB-231 cells. Data are presented as the mean \pm SEM of three independent experiments. ${ }^{*} \mathrm{P}<0.05,{ }^{* * *} \mathrm{P}<0.01$ vs. control. (F) EGFR and MIF expression levels were determined by western blot analysis. SEM; standard error of the mean; DMSO, dimethyl sulfoxide; EGFR, epidermal growth factor receptor; MIF, tumor metastasis-associated protein; CDK4, cyclin-dependent kinase 4; DAPT, Duration of Dual Antiplatelet Therapy; XN, xanthohumol; Ctrl, control.

western blot analysis of certain cell cycle associated proteins. There was a notable increase in p21WAF1/CIP1 expression levels in MCF-7 cells as the concentration of $\mathrm{XN}$ treatment increased, in addition to an increase in p21WAF1/CIP1 expression levels between the control and treatment groups in MDA-MB-231 cells (Fig. 3A). As anticipated, from an increase in p21WAF1/CIP1 expression levels, flow cytometry experiments revealed that cells responded in time-dependent and dose-dependent manners to $\mathrm{XN}$, through arresting cells in the $G_{0} / G_{1}$ phase of the cell cycle (Fig. 3B). Cells were treated with $\mathrm{XN}$ for 24 or $48 \mathrm{~h}$, and the percentage of control cells in $\mathrm{G}_{0} / \mathrm{G}_{1}$ phase was 51.1 and $10 \%$; however, following treatment with $20 \mu \mathrm{M} \mathrm{XN}, 70.6$ and $24.8 \%$ of the cells were in the $\mathrm{G}_{0} / \mathrm{G}_{1}$ phase. Cell cycle arrest was confirmed by a decrease in CDK4 and cyclin D1 expression levels in the MCF-7 and MDA-MB-231 cells (Fig. 3A). As a consequence of $G_{0} / G_{1}$ phase cell cycle arrest, the present study investigated whether $\mathrm{XN}$ inhibits breast cancer cells by inducing apoptosis; this was determined by an Annexin V/PI assay and cleavage of PARP-1, caspase-3 and Bcl-xL and Bcl-2 expression levels. As presented in Fig. 4 (a representative experiment), following exposure to various media (DMEM, XN or DAPT for $48 \mathrm{~h}$, the percentage of apoptotic cells in the XN treated groups increased significantly in comparison with the control groups. DAPT was also revealed to induce the apoptosis of breast cancer cells; however, the $\mathrm{XN}$ treatment groups contained a higher number of apoptotic cells compared with the DAPT treated groups. Apoptosis assessed by western blot assay demonstrated the same trends as the Annexin-V/PI assay (Fig. 4A and B). An increase in cleaved caspase-3 and cleaved PARP was revealed with increasing doses of $\mathrm{XN}$ and DAPT, suggesting that the cells went through the caspase 
A

MCF-7
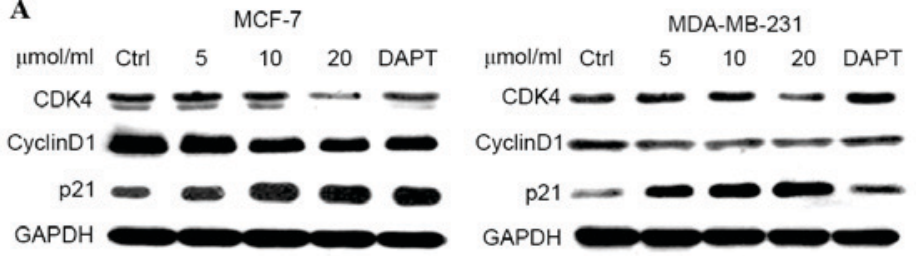

B

MCF-7-24 h
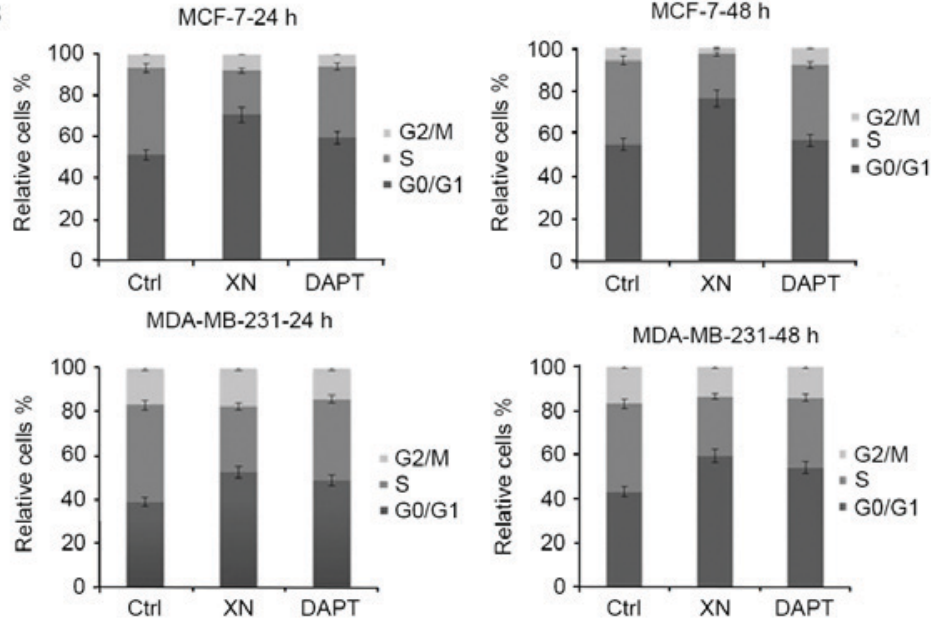

Figure 3. XN arrests the cell cycle in the $\mathrm{G}_{0} / \mathrm{G}_{1}$ phase. (A) $\mathrm{XN}$ regulated cell cycle protein expression levels were detected by western blotting. (B) MCF-7 and MDA-MB-231 cells were harvested for cell cycle analysis using PI staining. PI, propidium iodide; CDK4, cyclin-dependent kinase 4; DAPT, Duration of Dual Antiplatelet Therapy; Ctrl, control; XN, xanthohumol.

A
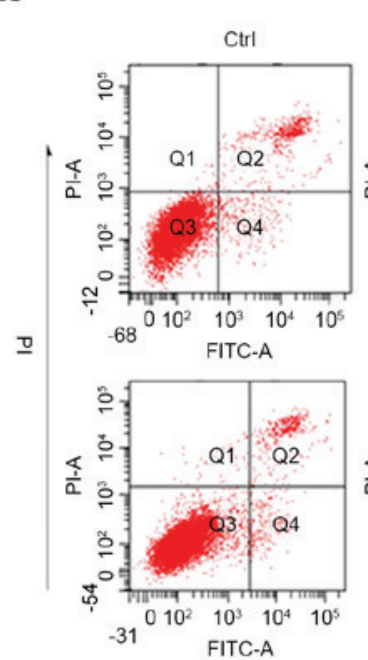

$\mathrm{XN}$
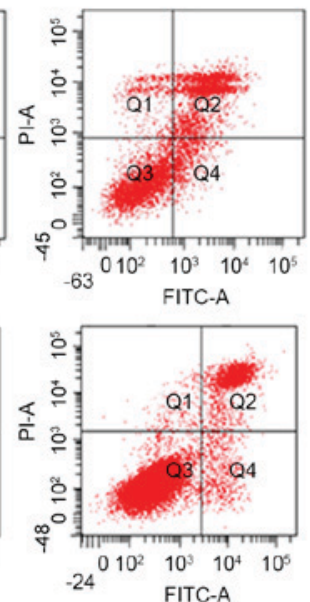

DAPT
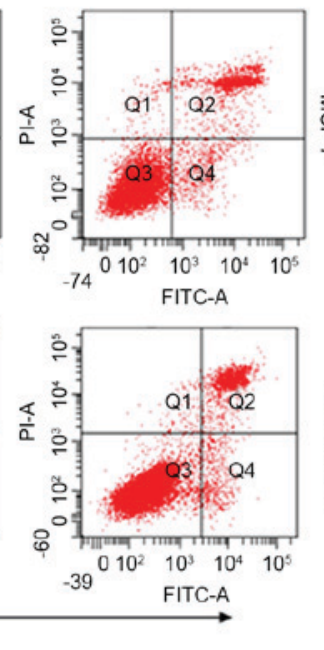

B
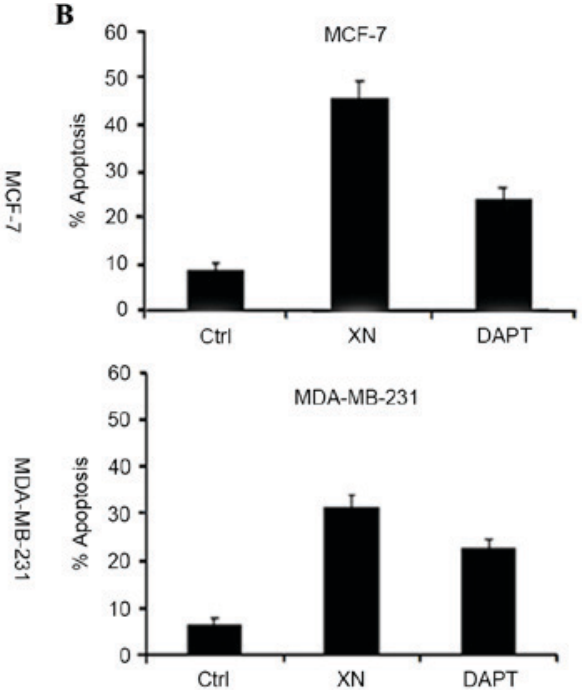

C

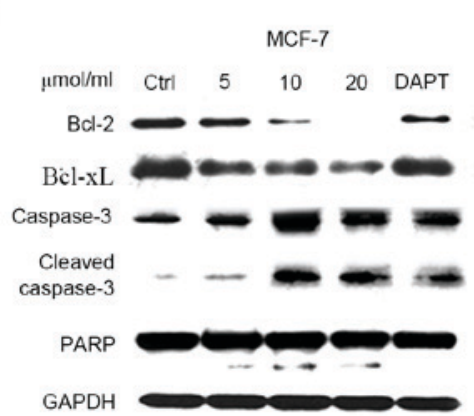

Annexin V

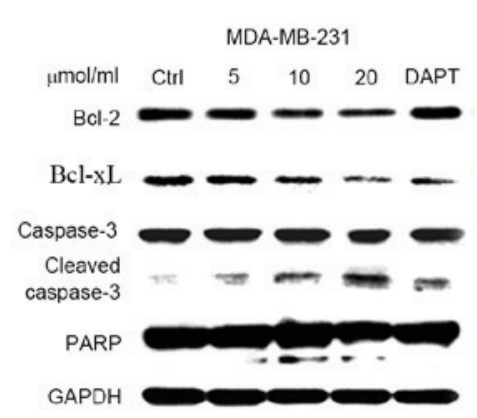

Figure 4. XN promote apoptosis of breast cells. (A) MCF-7 and MDA-MB-231 cells were harvested for apoptotic analysis using Annexin V-FITC staining. (B) Quantification of apoptosis. Data are presented as the mean \pm SD error of the mean of three independent experiments. (C) Apoptosis associated proteins $B c l-2, B c l-x L$ and caspase-3 and cleaved PARP were analyzed by western blotting. GAPDH was used as the control. FITC, fluorescein isothiocyanate; FITC-A, FITC-annexin; Ctrl, control; XN, xanthohumol; DAPT, Duration of Dual Antiplatelet Therapy; PI-A, propidium iodide annexin; Bcl-2, B cell lymphoma-2; $B c l-x L$, B cell lymphoma extra 1; PARP, poly (ADP-ribose) polymerase. 
A

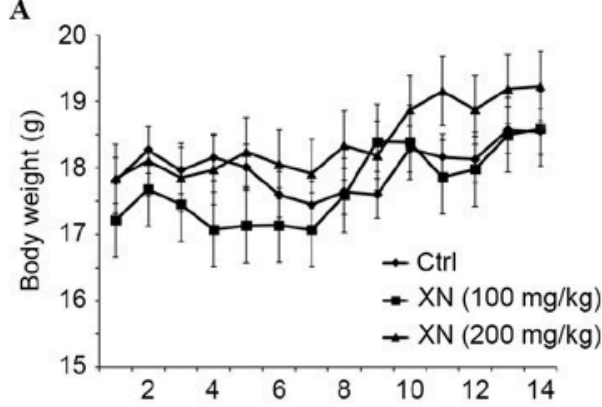

D

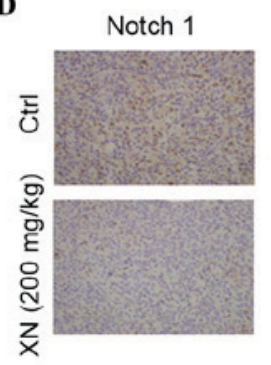

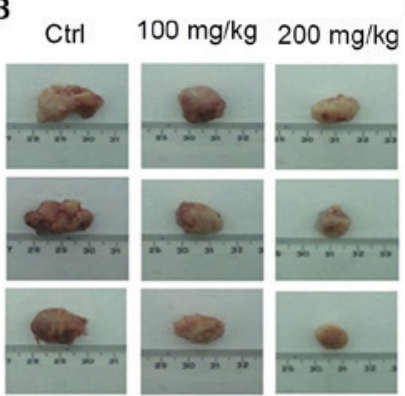

C

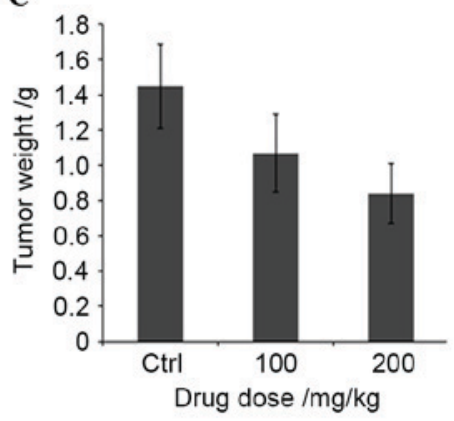

E
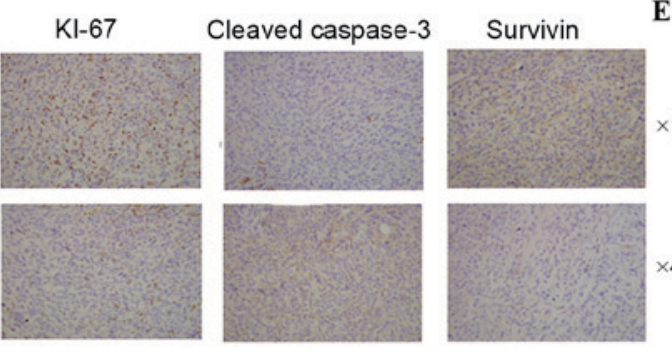

E Ctr

XN $(200 \mathrm{mg} / \mathrm{kg})$

$\times 10$
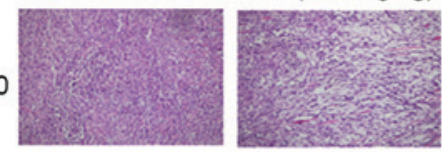

$\times 40$
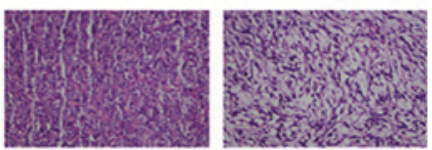

Figure 5. XN inhibited tumor growth in vivo. (A) Total average mouse weights. 4T1 cells $\left(1 \times 10^{5}\right)$ were subcutaneously grafted to 8 -week-old BALB/c mice. (B) Images of the tumors. (C) Tumor sizes of BALB/c mice treated with the control vehicle or $\mathrm{XN}$ as indicated. (D) Immunohistochemistry analysis for protein expression (x10). (E) Hematoxylin and eosin staining (x10 and x40) revealed the tumor tissues of mice. Ctrl, control; XN, xanthohumol.

cascade-mediated apoptotic pathway (Fig. 4C). These results indicated that $\mathrm{XN}$ exerts an inhibitory effect on cell proliferation and also promotes cell apoptosis.

XN effects mouse tumor growth and Notch 1 protein expression levels in vivo. In order to evaluate whether $\mathrm{XN}$ downregulation affects tumor growth in vivo, BALB/c mice were used as an in vivo model of mammary carcinoma. A mouse tumor model was generated by endermic injection of 4T1 murine mammary cells. Mice treated by oral gavage with XN three times a week did not exhibit any symptoms of toxicity, and no effects were observed in the body weight profiles when $\mathrm{XN}$ treated mice were compared with vehicle-fed controls (data not presented). At the time of necropsy, all animals were examined for gross pathology, and no evidence of edema or abnormal organ size in target and non-target organs was observed.

There was a significant difference in mouse tumor model weight between the control and the $200 \mathrm{mg} / \mathrm{kg} \mathrm{XN-fed} \mathrm{group}$ (Fig. 5A). Additionally, a marked decrease in tumor size in a dose dependent manner was revealed (Fig. 5B): Tumor weight decreased 27.22 and $46.79 \%$ following various XN treatments (100 and $200 \mathrm{mg} / \mathrm{kg}$ ), respectively (Fig. 5C). These results demonstrated that $\mathrm{XN}$ effectively inhibited breast tumor growth in vivo.

In the present study, the possibility of $\mathrm{XN}$ serving a role in Notchl-associated protein expression in vivo was investigated. The expression levels of Notch 1, Ki-67, survivin and caspase-3 by immunohistochemistry was determined. Fig. 5D demonstrates that XN inhibits the expression of Notchl and Ki-67. Survivin was downregulated and cleaved caspase-3 was upregulated in XN treated tissues (Fig. 5D). Hematoxylin and eosin staining revealed that $\mathrm{XN}$ produced obvious cell injury in the tumor tissues of mice (Fig. 5E). These results demonstrated that XN efficiently inhibited the growth of tumors and promoted tumor cell apoptosis, which further indicates that $\mathrm{XN}$ has an antitumor effect.

\section{Discussion}

The Notch signaling pathway decides cell fate, an important carcinogenic factor of breast cancer $(7,26)$. Notchl expression levels are connected to breast cancer cell proliferation and survival (27). Farnie and Clarke (28) reported that aberrant activation of the Notch signaling pathway is an early event in breast cancer, and high expression levels of the Notch 1 intracellular domain was indicative of a reduced time to five-year post-surgical recurrence. Therefore, the Notch signaling pathway may represent a breast cancer novel therapeutic target. Notch signaling may be downregulated via inhibition of Notch ligands, inhibiting tumor cell proliferation (29). G-secretase inhibitors may be used to block Notch signaling and have previously been applied in clinical studies $(30,31)$. However, one of the major challenges is to eliminate unwanted toxicity associated with $\gamma$-secretase inhibitors (32); thus, alternative Notch inhibitors must be identified.

$\mathrm{XN}$, a product of hops, may inhibit cell growth and induce apoptosis in numerous types of human cancer, including breast cancer $(19-23,33)$. Previous studies into the biological activity of XN have revealed their antiproliferative activity and possible antitumor activity (34). Guerreiro et al (33) suggested that XN may modulate alkaline phosphatase isoenzymes in MCF-7 breast cancer cells, and that alkaline phosphatase loss was associated with increased cell proliferation. In 2012, Cho et al (35) reported that XN induced cancer cell specific apoptosis in MCF-7 human breast cancer cells. These results raise the possibility that $\mathrm{XN}$ may be a potential therapeutic agent in human breast cancer. There are currently few studies that address this question directly and this appears to be an area worthy of further investigation. 
Notchl acts as an oncogene in breast cancer; therefore, inhibition of Notchl expression may lead to inhibition of cell growth and apoptotic cell death in breast cancer cells $(10,33)$. The present study demonstrated that proliferation inhibition and apoptosis induction by $\mathrm{XN}$ are specific to cancer cells with a constitutively inhibited Notch 1 signaling pathway; DAPT was used as a positive control. An MTT assay and light microscopy (Fig. 2A and B) indicated that $\mathrm{XN}$ inhibited cell proliferation in breast cancer cell lines. Proliferation associated proteins, including c-Myc and survivin, expression levels were determined (Fig. 2C). MD-MBA-231 cells, invasive breast cancer cells, were used to assess the ability to modulate cell migration through Boyden chamber porous membranes. As presented in Fig. 2D, cells treated with XN prevented cell migration to the lower chamber in a Boyden chamber assay, which was significantly different compared with the control. Activation of the EGFR induced signaling pathway correlated with cancer metastasis in various tumors, including breast carcinoma (36). Dai et al (37) reported that Notch and EGFR signaling pathways are positively associated with human breast cancer. The Notch signaling pathway inhibitor may also inhibit EGFR expression. Furthermore, additional factors, including MIF, which inhibits cell migration and $\mathrm{XN}$, increased MIF expression.

The results of the present study indicate that MCF-7 and MDA-MB-231 cells were inhibited in the $G_{0} / G_{1}$ phase of the cell cycle, and underwent induced apoptosis when treated with XN. Downstream target genes of the Notch signaling pathway are also involved in cell cycle arrest and apoptotic pathway $(14,15,18)$. Cyclin D1 and CDK4 phosphorylate key cell cycle proteins, controlling the $G_{1}-S$ cell cycle phases; $p 21$ is an ubiquitous inhibitor of kinase CDK, which guides cell cycle arrest (38-40). The Hes/Hey genes are Notch target genes, which are basic helix-loop-helix repressors (4). A number of additional genes, including p21 and cyclin D1, have been suggested to be direct targets of the Notch signaling pathway $(13,14)$.

In breast cancer, the nuclear antigen $\mathrm{Ki}-67$ has previously been applied widely for comparison of cell proliferation between tumor samples in immunohistochemical assessment $(41,42)$. The immunohistochemical evaluations revealed that XN decreased Notch 1, Ki-67 and survivin expression levels, and increased caspase-3 expression. The present study demonstrated that XN may inhibit breast tumor growth and promote apoptosis (Fig. 5).

In conclusion, the present study revealed that $\mathrm{XN}$ possesses antiproliferative, anti-metastatic and pro-apoptotic effects in breast cancer cells. It was also revealed that $\mathrm{XN}$ inhibits tumor growth using an in vivo tumor growth assay. The results of the present study demonstrated that $\mathrm{XN}$ may be a promising chemopreventive candidate for breast cancer treatment via inhibition of the Notch signaling pathway. These results suggest that $\mathrm{XN}$ requires further study into its potential therapeutic role in breast cancer treatment.

\section{Acknowledgements}

The present study was supported by the Science and Technology Support Projects of Gansu Province, China (grant no. 2010GS05414). The authors would like to thank Dr Yumen Tuopu, Science Development and Technology Co., Ltd., for providing XN, and Dr. Diane Hayward (The Johns Hopkins
University, Baltimore, MD, USA) for providing the 23A plasmid, which contained four copies of the CBF1-binding elements in pGL2 Luciferase Reporter Vectors.

\section{References}

1. Guo H, Wu F, Wang Y, Yan C and Su W: Overexpressed ubiquitin ligase Cullin7 in breast cancer promotes cell proliferation and invasion via down-regulating p53. Biochem Biophys Res Commun 450: 1370-1376, 2014.

2. Keyaerts M, Xavier C, Heemskerk J, Devoogdt N, Everaert H, Ackaert C, Vanhoeij M, Duhoux FP, Gevaert T, Simon P, et al: Phase I study of 68Ga-HER2-Nanobody for PET/CT assessment of HER2-expression in breast carcinoma. J Nucl Med 57: 27-33, 2016

3. Al-Hussaini H, Subramanyam D, Reedijk M and Sridhar SS: Notch signaling pathway as a therapeutic target in breast cancer. Mol Cancer Ther 10: 9-15, 2011.

4. Yuan X, Zhang M, Wu H, Xu H, Han N, Chu Q, Yu S, Chen Y and Wu K: Expression of Notch1 correlates with breast cancer progression and prognosis. PLoS One 10: e0131689, 2015.

5. Roy M, Pear WS and Aster JC: The multifaceted role of Notch in cancer. Curr Opin Genet Dev 17: 52-59, 2007.

6. Palmer WH and Deng WM: Ligand-independent mechanisms of Notch activity. Trends Cell Biol 25: 697-707, 2015.

7. Artavanis-Tsakonas S, Rand MD and Lake RJ: Notch signaling: Cell fate control and signal integration in development. Science 284: 770-776, 1999.

8. Kopan R and Ilagan MX: The canonical Notch signaling pathway: Unfolding the activation mechanism. Cell 137: 216-233, 2009.

9. Radtke F and Raj K: The role of Notch in tumorigenesis: Oncogene or tumour suppressor. Nat Rev Cancer 3: 756-767, 2003.

10. Robinson DR, Kalyana-Sundaram S, Wu YM, Shankar S, Cao X, Ateeq B, Asangani IA, Iyer M, Maher CA, Grasso CS, et al: Functionally recurrent rearrangements of the MAST kinase and Notch gene families in breast cancer. Nat Med 17: 1646-1651, 2011.

11. Liao WR, Hsieh RH, Hsu KW, Wu MZ, Tseng MJ, Mai RT, Wu Lee YH and Yeh TS: The CBF1-independent Notch1 signal pathway activates human c-myc expression partially via transcription factor YY1. Carcinogenesis 28: 1867-1876, 2007.

12. Xia J, Li Y, Yang Q, Mei C, Chen Z, Bao B, Ahmad A, Miele L, Sarkar FH and Wang Z: Arsenic trioxide inhibits cell growth and induces apoptosis through inactivation of Notch signaling pathway in breast cancer. In J Mol Sci 13: 9627-9641, 2012.

13. Rangarajan A, Talora C, Okuyama R, Nicolas M, Mammucari C, Oh H, Aster JC, Krishna S, Metzger D, Chambon P, et al: Notch signaling is a direct determinant of keratinocyte growth arrest and entry into differentiation. EMBO J 20: 3427-3436, 2001.

14. Ling $\mathrm{H}$ and Jolicoeur $\mathrm{P}$ : Notch-1 signaling promotes the cyclinD1-dependent generation of mammary tumor-initiating cells that can revert to bi-potential progenitors from which they arise. Oncogene 32: 3410-3419, 2013.

15. Palomero TL, Lim WK, Odom DT, Sulis ML, Real PJ, Margolin A, Barnes KC, O'Neil J, Neuberg D, Weng AP, et al: Notch1 directly regulates c-MYC and activates a feed-forward-loop transcriptional network promoting leukemic cell growth. Proc Natl Acad Sci USA 103: 18261-18266, 2006.

16. Ramdass B, Maliekal TT, Lakshmi S, Rehman M, Rema P, Nair P, Mukherjee G, Reddy BK, Krishna S and Radhakrishna Pillai M: Coexpression of Notch1 and NF-kappaB signaling pathway components in human cervical cancer progression. Gynecol Onco 104: 352-361, 2007.

17. Xie M, He CS, Wei SH and Zhang L: Notch-1 contributes to epidermal growth factor receptor tyrosine kinase inhibitor acquired resistance in non-small cell lung cancer in vitro and in vivo. Eur J Cancer 49: 3559-3572, 2013.

18. Sionov RV, Kfir-Erenfeld S, Spokoini R and Yefenof E: A role for bcl-2 in Notch1-dependent transcription in thymic lymphoma cells. Adv Hematol 2012: 435241, 2012.

19. Colgate EC, Miranda CL, Stevens JF, Bray TM and Ho E: Xanthohumol, a prenylflavonoid derived from hops induces apoptosis and inhibits NF-kappaB activation in prostate epithelial cells. Cancer Lett 246: 201-209, 2007.

20. Gerhauser C, Alt A, Heiss E, Gamal-Eldeen A, Klimo K, Knauft J, Neumann I, Scherf HR, Frank N, Bartsch H and Becker H: Cancer chemopreventive activity of Xanthohumol, a natural product derived from hop. Mol Cancer Ther 1: 959-969, 2002. 
21. Gonçalves P, Araújo JR, Pinho MJ and Martel F: In vitro studies on the inhibition of colon cancer by butyrate and polyphenolic compounds. Nutr Cancer 63: 282-294, 2011.

22. Nozawa H: Xanthohumol, the chalcone from beer hops (Humulus lupulus L.), is the ligand for farnesoid $\mathrm{X}$ receptor and ameliorates lipid and glucose metabolism in KK-A(y) mice. Biochem Biophys Res Commun 336: 754-761, 2005.

23. Pan L, Becker H and Gerhäuser C: Xanthohumol induces apoptosis in cultured 40-16 human colon cancer cells by activation of the death receptor- and mitochondrial pathway. Mol Nutr Food Res 49: 837-843, 2005.

24. Shi J, Chen J, Serradji N, Xu X, Zhou H, Ma Y, Sun Z, Jiang P, Du Y, Yang J, et al: PMS1077 sensitizes TNF- $\alpha$ induced apoptosis in human prostate cancer cells by blocking NF- $\mathrm{BB}$ signaling pathway. PLoS One 8: e61132, 2013

25. Liu P, Zhao L, Xu X, Liu F, Zhang W, Zhou C, Chen J, Pan Y, Du Y, Yang J and Wang Q: N6-substituted adenosine analogues, a novel class of JAK2 inhibitors, potently block STAT3 signaling in human cancer cells. Cancer Lett 354 43-57, 2014.

26. Zhang X, Samadi AK, Roby KF, Timmermann B and Cohen MS: Inhibition of cell growth and induction of apoptosis in ovarian carcinoma cell lines $\mathrm{CaOV} 3$ and SKOV3 by natural withanolide Withaferin A. Gynecol Oncol 124: 606-612, 2012.

27. Pei J and Wang B: Notch-1 promotes breast cancer cells proliferation by regulating LncRNA GAS5. Int J Clin Exp Med 8: 14464-14471, 2015.

28. Farnie G and Clarke RB: Breast stem cells and cancer. Ernst Schering Found Symp Proc: 141-153, 2006.

29. Rasul S, Balasubramanian R, Filipović A, Slade MJ, Yagüe E and Coombes RC: Inhibition of gamma-secretase induces $\mathrm{G} 2 / \mathrm{M}$ arrest and triggers apoptosis in breast cancer cells. Br J Cancer 100: 1879-1888, 2009.

30. Shih IeM and Wang TL: Notch signaling, gamma-secretase inhibitors and cancer therapy. Cancer Res 67: 1879-1882, 2007.

31. Beel AJ and Sanders CR: Substrate specificity of gamma-secretase and other intramembrane proteases. Cell Mol Life Sci 65: $1311-1334,2008$

32. van Es JH, van Gijn ME, Riccio O, van den Born M, Vooijs M, Begthel H, Cozijnsen M, Robine S, Winton DJ, Radtke F and Clevers H: Notch/gamma-secretase inhibition turns proliferative cells in intestinal crypts and adenomas into goblet cells. Nature 435: 959-963, 2005.
33. Guerreiro S, Monteiro R, Martins MJ, Calhau C, Azevedo I and Soares R: Distinct modulation of alkaline phosphatase isoenzymes by 17beta-estradiol and xanthohumol in breast cancer MCF-7 cells. Clin Biochem 40: 268-273, 2007.

34. Mendes V, Monteiro R, Pestana D, Teixeira D, Calhau C and Azevedo I: Xanthohumol influences preadipocyte differentiation: Implication of antiproliferative and apoptotic effects. J Agric Food Chem 56: 11631-11637, 2008.

35. Cho MY, Park SY, Park S, Lee YR, Han GD and Kim JA: Geranyl derivative of phloroacetophenone induces cancer cell-specific apoptosis through Bax-mediated mitochondrial pathway in MCF-7 human breast cancer cells. Biol Pharm Bull 35: 98-104, 2012.

36. Hsieh CY, Tsai PC, Tseng CH, Chen YL, Chang LS and Lin SR: Inhibition of EGF/EGFR activation with naphtho[1,2-b] furan-4,5-dione blocks migration and invasion of MDA-MB-231 cells. Toxicol In Vitro 27: 1-10, 2013.

37. Dai J, Ma D, Zang S, Guo D, Qu X, Ye J and Ji C: Cross-talk between Notch and EGFR signaling in human breast cancer cells. Cancer Invest 27: 533-540, 2009.

38. Lange C, Huttner WB and Calegari F: Cdk4/cyclinD1 overexpression in neural stem cells shortens G1, delays neurogenesis, and promotes the generation and expansion of basal progenitors. Cel Stem Cell 5: 320-331, 2009.

39. Waga S, Hannon GJ, Beach D and Stillman B: The p21 inhibitor of cyclin-dependent kinases controls DNA replication by interaction with PCNA. Nature 369: 574-578, 1994

40. Xiong Y, Hannon GJ, Zhang H, Casso D, Kobayashi R and Beach D: p21 is a universal inhibitor of cyclin kinases. Nature 366: 701-704, 1993.

41. Dowsett M, Nielsen TO, A'Hern R, Bartlett J, Coombes RC, Cuzick J, Ellis M, Henry NL, Hugh JC, Lively T, et al: Assessment of Ki67 in breast cancer: Recommendations from the International Ki67 in Breast Cancer working group. J Natl Cancer Inst 103: 1656-1664, 2011.

42. Basu S, Combe K, Kwiatkowski F, Caldefie-Chézet F, Penault-Llorca F, Bignon YJ and Vasson MP: Cellular expression of cyclooxygenase, aromatase, adipokines, inflammation and cell proliferation markers in breast cancer specimen. PLoS One 10: e0138443, 2015.

This work is licensed under a Creative Commons Attribution-NonCommercial-NoDerivatives 4.0 International (CC BY-NC-ND 4.0) License. 